\title{
Oil Price Fluctuations and Firm Performance in an Emerging Market: Assessing Volatility and Asymmetric Effect
}

\author{
Hawati Janor, Aisyah Abdul-Rahman, Ehsan Housseinidoust, and Ruzita Abdul Rahim, Member, IACSIT
}

\begin{abstract}
This study examines the impact of oil price volatility on firm performance in the context of an emerging market, Malaysia. The effect of crude oil price on the performance is examined for the period of January 1986 to December 2011 using GARCH and EGARCH models reflecting the evaluation on volatility and asymmetric effects. Results indicate the significant effect of oil price volatility on stock market volatility and also the asymmetric effects. For policy makers, the findings help to clarify the dilemma of whether the government should subsidize or totally depend on global oil prices in ensuring the sustainability and competitiveness of Malaysian companies. In addition, the results may assist businessmen in managing cost structures in the event of rising oil prices in relation to both short term and long term planning and provide investors with a better picture of the exposure to oil price risks when investing in Malaysian companies.
\end{abstract}

Index Terms-Asymmetric effect, firm performance, oil price, volatility.

\section{INTRODUCTION}

Studying the impact of oil prices and performance in stock market has been an active and growing research area. The volatile world oil prices and oil prices in Malaysia (as depicted in Fig. 1 and Fig. 2, respectively), alongside the ambiguous results of studies on the impact of oil price variations on market performance have heightened research interest in this area. Since the pioneering study of Hamilton [1] on the impact of crude oil prices on US recessions, many studies have examined the impact of oil price changes on macroeconomic variables. Besides affecting these aggregate macroeconomic indicators directly, price of crude oil may also affecting firms' performance through the effects on operational costs, and thus their revenues. Hence, positive crude oil price shocks would negatively affect the cash flows and market values of companies. Since asset prices are regarded as the discounted value of future firms' earnings or cash flows, thus such negative effects on firms' performance would cause an immediate decline in the overall stock market returns (Huang et al. [2], Nandha and Faff [3]). According to Huang et al. [2], the rising oil prices, on one hand, in the absence of complete substitution affects the factors of

Manuscript received March 14, 2013, revised May 17, 2013. This work was supported in part by the Faculty of Economics and Management, National University of Malaysia under Grant EP-013-2009.

Hawati Janor is with the Finance, Financial Services and Risk Management Department, Faculty of Economics and Management, National University of Malaysia, 43600, UKM Bangi, Selangor, Malaysia (e-mail: hawati@ukm.my).

Aisyah Abdul Rahman and Ruzita Abdul Rahim are with the Finance and Risk Management and Insurance Department, Faculty of Economics and Management, National University of Malaysia, 43600, UKM Bangi, Selangor, Malaysia (e-mail: eychah@ukm.my, ruzitaar@ukm.my).

Ehsan Housseinidoust is with the Faculty of Economics and Management, National University of Malaysia, 43600, UKM Bangi, Selangor, Malaysia. production, resulting in increased costs relating to business operations. Consequently, higher business costs reduce cash flows, thus reducing stock prices. On the other hand, rising oil prices also affect the discount rate employed in the asset pricing formula in stock valuation, since it is often used as an indicator of inflationary pressures. Despite the conceptual development given by Huang et al. [2], many empirical studies that examine the relationship between oil fluctuations and stock returns provide inconclusive evidence, among others Jones and Kaul [4], Huang et al. [2], Evangelia [5], Juncal and Fernando [6] and Mohanty [7]. Hence, warrants further studies to be undertaken on this topic.

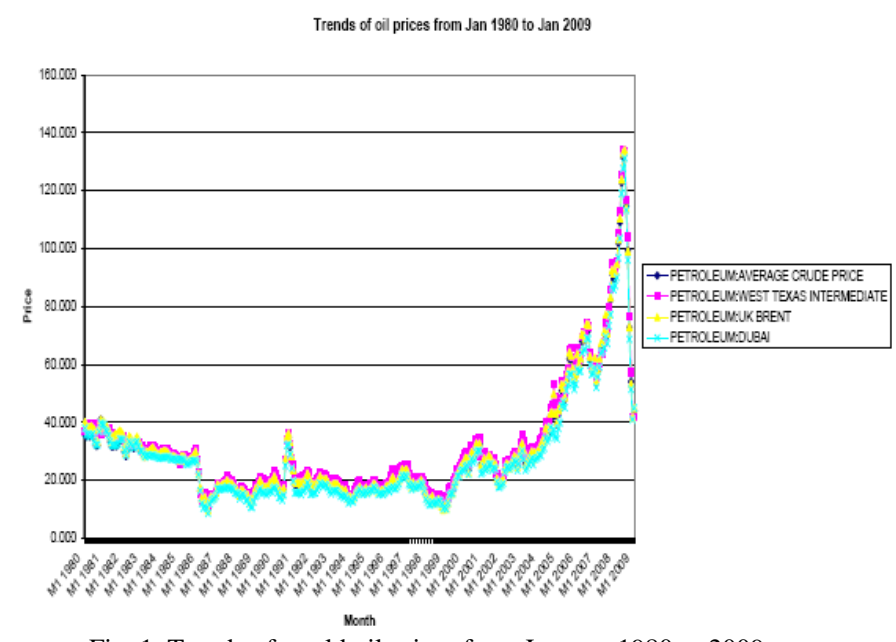

Fig. 1. Trends of world oil prices from January 1980 to 2009.

A strand of literature related to oil prices focuses on the effect of oil price volatility on the volatility of stock markets (Arouri, Lahiani and Nguyen [8] and Masih, Peters \& De Mello [9]. While the general impacts of oil price volatility on economic and stock markets remains to be demonstrated, an analysis of the impact of oil price volatility on the volatility of stock returns in emerging market such as Malaysia, is worth conducting for two principal reasons. Firstly, given that the impact of oil prices is profound particularly in development and structure of financial markets in developed economies and emerging markets, make it imperative to investigate the impact of oil price volatility on stock returns in Malaysia. Understanding the issue on Malaysia is potentially beneficial, as it is likely to exhibit characteristics different from those observed in well-documented developed markets. Secondly, given the fact that Malaysia is a net oil exporter, the analysis of Malaysia is a worthwhile examination, since several studies have argued that the effect of oil prices on the economy depends on whether the economy is a net oil importer or net oil exporter. For the net oil importer, an increase in oil prices may have a negative impact on its exports as it increases production costs. However, the impact can also be positive if the potential 
output level and actual output level have not reached a threshold level at which oil prices can negatively impact output

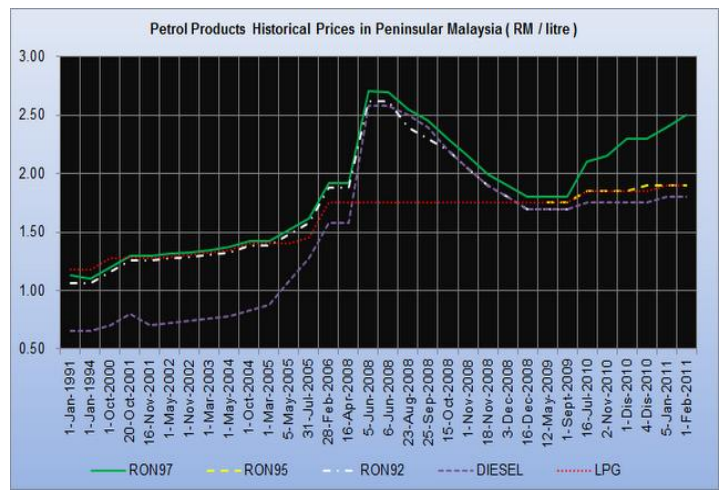

Fig. 2. Trends of oil prices in Malaysia from January 1991 to $2009^{1}$.

(Jayaraman and Choong [10]). On the other hand, for the net oil exporter, the increase in COP may contribute to improvement in terms of trade and increases in export earnings. Since many studies have focused on net oil importing countries, it is important to examine the issue in the Malaysian stock market. Table I highlights the increasing trend of the production and net exports of petroleum for Malaysia. For the exports, the trend is increasing since 1981 and similarly for the oil production. In 2008, total oil production amounted to no less than 728 thousand barrels per day, increasing from the previous year figure.

Given that the presence of asymmetric effects phenomenon is found within several studies investigating the impact of oil prices on stock returns (Basher and Sadorsky [11], Mohanty et al. [7]) thus, studies that considers such phenomena provide more insights on the relationship between the two variables. Hence, with a specific focus on the Malaysian market, the objective of this study is to examine the impact of oil price on stock returns which takes into consideration volatility and asymmetric effects. The paper proceeds as follows. The remaining sections consist of a literature review, a summary of the research methodology employed, and the results of the analyses, followed by the final section, which presents the conclusions.

\section{LITERATURE REVIEW}

A large body of literature has examined the impact of oil price changes on stock returns; however the evidence has been mixed.

Huang et al. [2] and Juncal and Fernando [6] find that the return generated by oil prices have no impact on stock indices and there is no gain in considering the risk caused by fluctuating oil prices on stock markets. In contrast, Basher and Sadorsky [11] find robust evidence that the risks associated with changes in oil prices impact the performance of stock markets reflecting strong evidence of impact of oil prices on stock returns. They pointed out that the results show that emerging countries are subject to greater influence in the

\footnotetext{
${ }^{1}$ The RON92 has been phased out from the Malaysian petrol market since the official launch of RON95 petrol on September 1, 2009, with a price tag of RM1.80/liter, Several months before the official launching of the RON95, the price of RON92 was RM1.75.
}

oil market as more intensive use of energy than advanced economies mainly because of the greater efficiency achieved. Similar strong reaction of stock returns on oil price changes have been documented by studies such as Evangelia [5], Masih et al. [9] and Mohanty et al. [7] but only partial evidence has been documented by Jones and Kaul [4] who find that the reaction of Canadian and US stock prices to oil price shocks can be completely accounted for by the impact of these shocks on real cash flows but not fully accounted for Japan and the UK.

TABLE I: MALAYSIA'S OIL PRODUCTION AND EXPORTS

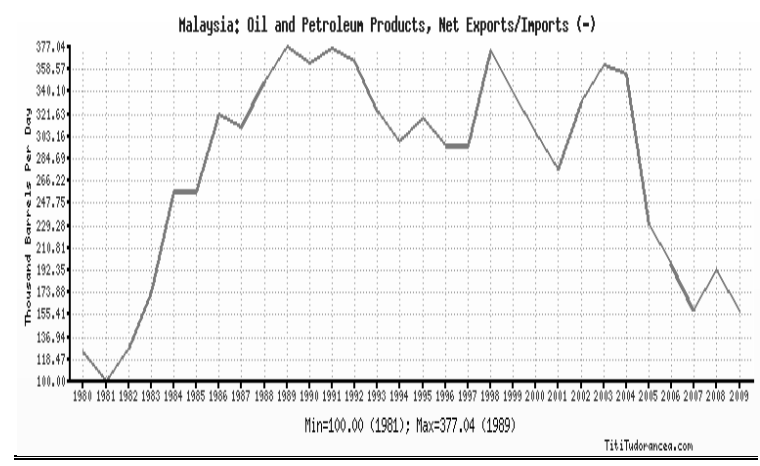

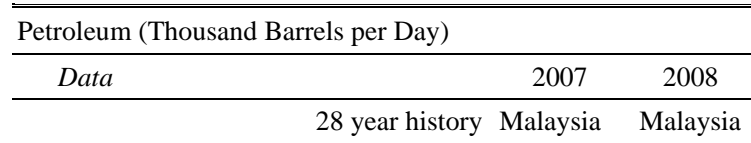

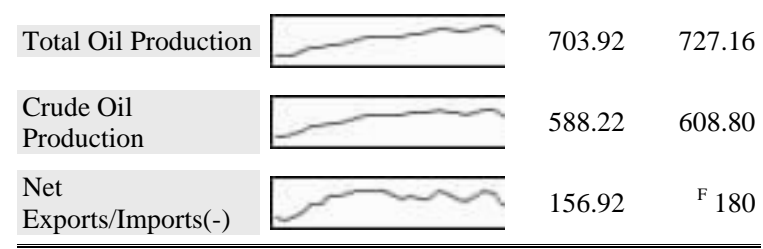

Source: Energy Information Administration (EIA) International Energy Annual

For Creece market, Evangelia [5] finds that oil price shocks have an effect on the industrial production index. In contrast, Juncal and Fernando [6] reveal that there is no co-integrating long-term relationship between oil prices and industrial production index for European countries. However, their study does not consider whether the volatility of the oil market influences industrial production index.

On the aspect of volatility, Hamilton [12] states that turbulence in oil prices causes the marginal effect of any given oil price change to be reduced, therefore, asymmetry might not exist when accounting for oil volatility. However, Federer [13] claims that part of the asymmetric relationship between oil price changes and output growth found in previous studies can be explained by the economy's response to oil price volatility. On the other hand, Sadorsky [14] finds that either an oil price change or its volatility has an impact on real stock returns. On the issue of volatility, Arouri et al. [8] examine Gulf Cooperation Council (GCC) countries over the period 2005-2010 and Masih et al. [9] on Korean market provide support on the importance of volatility in testing the relationship between the two variables. Also using data on GCC in examining impact of oil prices changes on stock returns from June 2005 to December 2009, Mohanty et al. [7] find that except for Kuwait, stock return for other five GCC countries react positively to changes in oil prices. Thus, a decline in oil prices has negative impact on stock returns and an increase in oil price has positive impact. Their results 
support previous studies which suggest that emerging stock markets operate under a different set of market forces, competitive environments and government regulations.

Literatures on the effect of oil prices has also found asymmetric effects in which both oil price hikes and falls are likely to have different effects on the stock markets (Basher and Sadorsky [11], Sadorsky [14]). Oil price hikes have a negative impact on stock returns but drops in oil prices do not necessarily have a positive impact. However studies such as Park and Ratti [15] and Nandha and Faff [3] do not find evidence on asymmetric effects in stock markets. Some explanations regarding the asymmetry puzzle come from investment uncertainty or sectoral shift channels. Uncertainty about energy prices may induce firms to postpone investment decisions, because of the uncertainty about future investment climate (Bernanke [16] where as the sectoral shifts view suggests that unemployment is, in part, the result of resources being reallocated from declining to expanding sectors of the economy. In addition, Ferderer [13] states that if oil price changes affect positively oil price volatility and if oil price volatility has a negative effect on the economy, then those explanations have a potential to explain the asymmetry puzzle.

\section{Methodology AND DATA}

In this study, we examine the effect of oil price volatility on the volatility of Malaysian stock market, one of the emerging markets in Asian region. We use Kuala Lumpur Composite Index (KLCI) to measure stock returns and monthly returns of the world crude oil price (COP) derived from West Texas Intermediate (WTI) for oil prices, due to the fact that it is most widely used indices in the world and used widely by previous studies. Moreover, Juncal and Fernando [6] state that most studies involving oil price issues utilize world crude oil prices quoted in USD. The monthly data used in this study are collected from Thompson-Reuters Data Stream. The study period spans from Jan-1986 to Dec-2011. The return on KLCI is computed by equation (1):

$$
R_{t}=\left(\frac{P_{t}}{P_{t-1}}\right)
$$

where, $R_{t}$ represents return at time t, and $P_{t}$ and $\mathrm{P}_{\mathrm{t}-1}$ represent value of index at the current period and previous period respectively.

In order to examine the volatility, we employ the Exponential Generalized Autoregressive Conditional Heteroscedasticity (EGARCH) model. We test for unit root of both variables, employing the augmented Dickey-Fuller (ADF) and Zivot-Andrews (ZA) [17]. ZA unit root test is used to test for robustness due to $i$. the results from ADF testing can be misleading when the time series data have structural break or level shift characteristics, ii. ZA test is capable of capturing the breakpoint(s) in the time series, as well as checking whether the time series is stationary or nonstationary, even in instances involving the presence of a structural break. Next, in order to identify the true distribution function for the error terms' distribution, the kernel density function is employed. After univariate framework, testing for the existence of the volatility market will be investigated by employing the EGARCH model. Results of this step will show whether there is asymmetry effect (or leverage effect) in the KLCI data generating process.

Next, based on multivariate framework, COP will be included in the EGARCH model in order to detect the magnitude of volatility. Hence, if the magnitude increases after the inclusion of COP, we can infer that the volatility of KLCI is increased as a result of oil price volatility. In the EGARCH model, which is empowered to capture the asymmetric effect of the financial markets, the increase in the volatility not only provides evidence concerning the negative impact of oil price volatility on the KLCI, but also provides information concerning whether negative oil price shocks have more significant impacts on this market than positive oil price shocks of the same magnitude.

\section{A. Unit root test}

The ADF tests the null hypothesis that a time series is $\mathrm{I}(1)$ against the alternative that is $\mathrm{I}(0)$, assuming that the dynamics in the data have an Autoregressive Moving Average structure (ARMA). One of the limitations of ADF is their inattention to the presence or absence of break at series under consideration. ZA suggested a procedure to check whether or not a series is stationary by the inclusion of break at series, allowing for the breakpoint, if it exists using dummy variables to capture the break

\section{B. GARCH and EGARCH Models}

Bollerslev [18] introduces the GARCH model, a conditional variance structure that follows the autoregressive form of conditional variance of the previous periods, as well as squared form of error term. The model is represented by equation (2):

$$
\sigma_{t}^{2}=\alpha_{0}+\sum_{j=1}^{q} \gamma_{j} \sigma_{t-j}^{2}+\sum_{i=1}^{p} \beta_{i} u_{t-i}^{2}
$$

where conditional variance of $\underline{u}$ at time $\underline{t}$ depends not only on the squared error term in the previous period, but also depends on its conditional variance in the previous periods The EGARCH model by Nelson [19], proposed asymmetric effects exist between positive and negative asset returns. The specification for conditional variance is represented in equation (3), as follows:

$$
\log \left(\sigma_{t}^{2}\right)=\omega+\sum_{i=1}^{p} \alpha_{i}\left|\frac{\varepsilon_{t-i}}{\sigma_{t-i}}\right|+\sum_{k=1}^{r} \gamma_{k}\left(\frac{\varepsilon_{t-k}}{\sigma_{t-k}}\right)+\sum_{j=1}^{q} \beta_{j} \log \left(\sigma_{t-j}^{2}\right)
$$

where $\gamma_{k}$ stands for capturing the asymmetric behavior of an asset return. EGARCH is capable of capturing the most important stylized features of stock return volatility, namely volatility clustering, negative correlation with return, logarithm normality and, under certain specifications, long memory. In addition, it is able to capture the "leverage" effect, as reported by Black and Fischer (1976), and indicating that shocks (i.e. bad news) have different influence. Essentially, the EGARCH model can determine whether the impact of a negative shock or bad news on the volatility of an asset return is higher than a positive shock or good news with the same magnitude. Furthermore, the logarithm form of the conditional variance implies that the leverage effect has an exponential form, hence the variance is non-negative. 


\section{RESULTS}

The descriptive statistics of the KLCI and the trends on the returns are depicted in Table II; Fig. 3 and Fig. 4 respectively. Fig. 3 shows that there are upward and downward movements of the KLCI fluctuations, implying that the mean and variance of this series is not fixed during time and the time series is nonstationary. Nevertheless, the return series, as shown in Fig. 4, does not exhibit any trend and its fluctuations are around the origin line, indicating a stationary process. However graphical inferences are not sufficient or reliable enough to reflect the stationarity level, hence robust tests through unit root testing are required. The results for the ADF and ZA unit root tests are provided in Table III which show that the KLCI is nonstationary at level, but the computed return series is stationary. The t-statistics is not significant, thus the null hypothesis of these tests cannot be accepted and the price series is nonstationary. However, the t-statistics of the return series is significant, indicating that the series is stationary. These findings are supported by the results of the ZA unit root test, confirming that the price series is nonstationary, while the return series is stationary, even with the presence of structural break in the time series. Therefore, due to the stationarity of the return series, this series will be used in the modeling process.

TABLE II: DESCRIPTIVE STATISTICS OF THE KLCI

\begin{tabular}{llll}
\hline \hline \multicolumn{3}{l}{ Kuala Lumpur Composite Index (KLCI) } & 1982-2011 \\
\hline Mean & Median & Maximum & Minimum \\
753.9731 & 719.61 & 1579.07 & 171.74 \\
Std. Dev. & Skewness & Kurtosis & Number of Observations \\
357.5736 & 0.371993 & 2.20611 & 312 \\
Return on KLCI & & \\
Mean & Median & Maximum & Minimum \\
0.004244 & 0.009094 & 0.294421 & -0.42897 \\
Std. Dev. & Skewness & Kurtosis & Number of Observations \\
0.075588 & -0.48223 & 7.266255 & 311 \\
\hline \hline
\end{tabular}

Next, the results of the kernel density function are depicted in Fig. 5, which includes the Normal distribution function and the Student's-t distribution function. As apparent from part $\underline{A}$ of this figure, the kernel density of Student's-t distribution provides a fitted plot with the KLCI return time series as compared to Normal distribution. A similar procedure is repeated in part $\mathrm{B}$ of this figure, which demonstrates the kernel density of the first difference of COP. Therefore, for modeling purposes, Student's-t distribution will be utilized. In summary, it is found that KLCI and COP are nonstationary, but their first difference forms are found to be stationary processes. In addition, the results of kernel density suggest that the Student's-t distribution would be the appropriate distribution function for the error term.

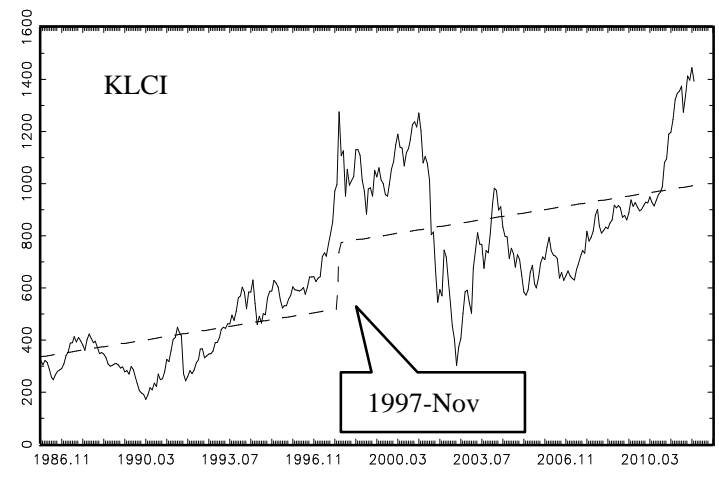

Fig. 3. KLCI price index.

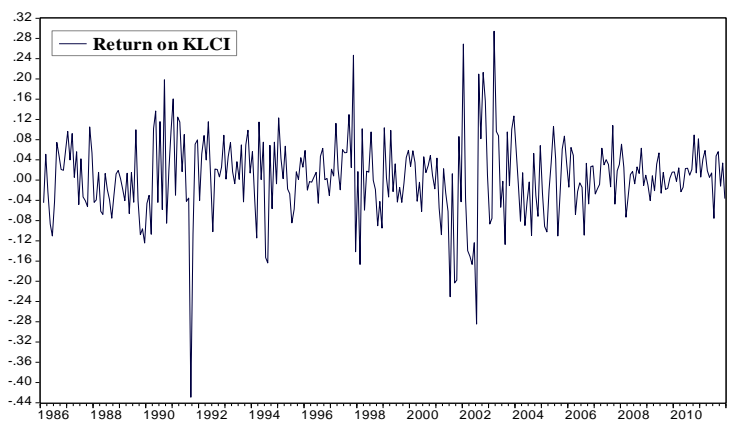

Fig. 4. Return on KLCI.

TABLE III: RESULTS OF THE ADF AND ZA UNIT ROOT TESTS

\begin{tabular}{|c|c|c|c|c|}
\hline \multirow{3}{*}{$\begin{array}{l}\text { Variable } \\
\mathrm{s}\end{array}$} & \multicolumn{4}{|c|}{ Test on the level form } \\
\hline & \multicolumn{2}{|c|}{$\mathrm{ADF}$} & \multicolumn{2}{|l|}{$\mathrm{ZA}$} \\
\hline & Intercept & $\begin{array}{l}\text { Trend \& } \\
\text { Intercept }\end{array}$ & Intercept & $\begin{array}{l}\text { Trend \& } \\
\text { Intercept }\end{array}$ \\
\hline KLCI & -1.2397 & -3.2277 & -4.7267 & -7.8231 \\
\hline \multirow{3}{*}{$\begin{array}{l}\text { Oil_Pric } \\
\text { e }\end{array}$} & 0.792548 & -0.98332 & -3.68807 & -3.61368 \\
\hline & \multicolumn{4}{|c|}{ Test on the first difference form } \\
\hline & $\mathrm{ADF}$ & & $\mathrm{ZA}$ & \\
\hline KLCI & $\begin{array}{l}-10.2447 * * \\
*\end{array}$ & $\begin{array}{l}-10.24022 * * \\
*\end{array}$ & $\begin{array}{l}-10.8302 * * \\
*\end{array}$ & $\begin{array}{l}-10.87145 * * \\
*\end{array}$ \\
\hline $\begin{array}{l}\text { Oil_Pric } \\
\mathrm{e}\end{array}$ & $\begin{array}{l}-5.07898 * * \\
*\end{array}$ & $-6.0796 * * *$ & $\begin{array}{l}-11.8877 * * \\
*\end{array}$ & $-10.0685^{* * *}$ \\
\hline
\end{tabular}

From Table IV, values reported in the brackets represent standard error of estimation. The GARCH model indicate the estimated coefficients of the variance equation are significant, hence the oil price time series follows a $\operatorname{GARCH}(1,1)$ procedure, showing the evidence of volatility clustering phenomenon exists in this time series.

TABLE IV: RESULTS FOR VOLATILITY ON THE COP

\begin{tabular}{ccc}
\hline \hline Mean Equation & & \\
\hline$C$ & $A R(1)$ & $M A(1)$ \\
-0.0018 & -0.8640 & 0.8833 \\
$(0.0032)$ & $(2477)$ & $(0.2318)$ \\
$C$ & & \\
Variance Equation & $\alpha_{1}$ & $\beta_{1}$ \\
$8.62 \mathrm{E}-05$ & 0.5258 & 0.6530 \\
$(6.05 \mathrm{E}-05)$ & $(0.0637)$ & $(0.0365)$ \\
\hline \hline
\end{tabular}

Table $\mathrm{V}$ presents the results for the univariate and multivariate framework. The upper part shows the results on the mean equation, while the lower part shows the results on the variance equation.

TABLE V: Results FOR UnIVARIATE AND MUltivariate MODELING OF KLCI

\begin{tabular}{lllll}
\hline \hline Type of & \multicolumn{5}{c}{ Mean Equation } & \\
model & $C$ & $A R(1)$ & $M A(1)$ & Oil_Price \\
\hline \multirow{2}{*}{ Model $(A)$} & 0.0070 & 0.0728 & - & - \\
& $(0.0035)$ & $(0.0625)$ & & $-8.04 \mathrm{E}-5$ \\
Model $(B)$ & 0.01000 & - & - & $(0.0001)$ \\
& $(0.0061)$ & & & \\
& Variance Equation & $\beta_{1}$ & $\gamma_{1}$ \\
& $\omega$ & $\alpha_{1}$ & 0.9401 & -0.2422 \\
Model $(A)$ & -0.6190 & 0.3802 & $(0.0299)$ & $(0.1121)$ \\
& $(0.2041)$ & $(0.0937)$ & 0.9422 & -0.2689 \\
Model $(B)$ & -0.6096 & 0.3837 & $(0.0299)$ & $(0.1107)$ \\
& $(0.2030)$ & $(0.0947)$ & & \\
\hline \hline
\end{tabular}

Model (A) and (B) represents the results for univariate modeling of KLCI return and multivariate modeling of KLCI return and COP respectively. The values reported in the 
brackets represent the standard errors of estimation. The EGARCH equation, $\left(\gamma_{k}\right)$ captures the asymmetric characteristics of the time series and the zero value of this coefficient represents the inexistence of asymmetric effects in one market. The negative significant value of this coefficient demonstrates evidence on the existence of an asymmetric effect in the market and, therefore, "bad news" will be more volatile than "good news" of the same magnitude.
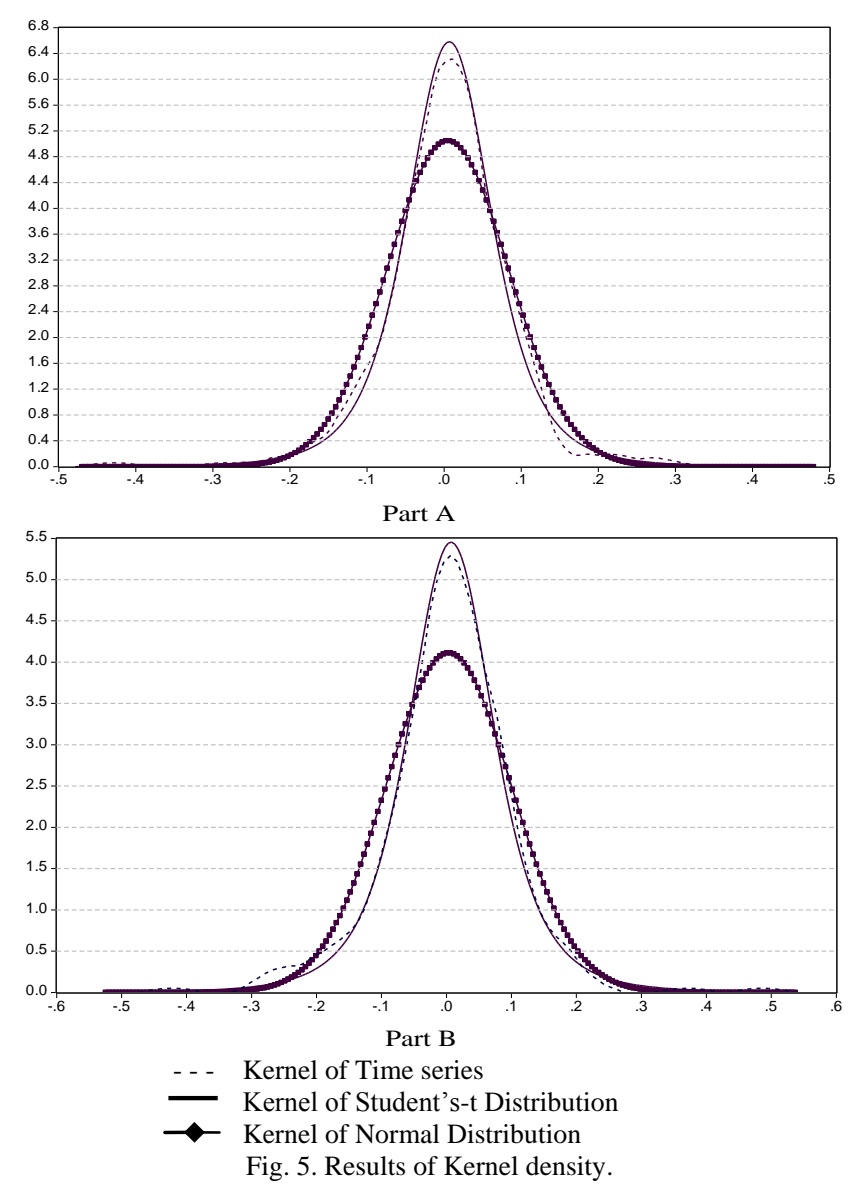

From model A, the significant results of the estimated coefficients of $\left(\alpha_{1}\right)$ and $\left(\beta_{1}\right)$ demonstrates the existence of volatility clustering in the computed return series of KLCI. The results also show that the coefficient $\left(\gamma_{1}\right)$, which is utilized to capture the leverage effect, is significant, thus providing the evidence of asymmetric behavior of the Malaysian stock market. Therefore, not only it is proven that there is volatility clustering in this market, but it is also demonstrated that responses of this market to negative shocks and positive shocks of the same magnitude are different, with negative shocks resulting in increased volatility of the KLCI.

The results from Model B demonstrate computed values for the coefficients of $\left(\alpha_{1}\right)$ and $\left(\beta_{1}\right)$ are significant, suggesting that there is volatility clustering in this model which is similar to the results from model $\mathrm{A}$, and also the magnitude of coefficient $\left(\gamma_{1}\right)$ has increased to -0.26 from -0.24 in Model A. This finding implies that the inclusion of oil price variable in the analysis has intensified the volatility of KLCI return series data.

\section{CONCLUSION}

Results of this study supported previous studies on the impact of oil price fluctuations on stock markets. The findings demonstrate that oil price shocks, particularly negative shocks, intensified the volatility of the KLCI and increased risks incurred through investment in this market during such periods. In addition, the existence of asymmetric effects on the impact of oil prices on stock returns provide support to previous studies that claim rising oil prices tend to have a greater impact than price declines.

The results provide useful information for managers in planning their cost structures in the event of increasing oil price; businessmen and financial managers to formulate short term, as well as long term strategies in relation to financial management; risk managers in forecasting techniques to analyze the impact of oil price changes; policy makers and regulators in decisions relating to monetary and market policies within Malaysia and investors, as it depicts their potential exposure to oil price risks when investing in Malaysian companies.

\section{REFERENCES}

[1] J. D. Hamilton, "Oil and the macroeconomy since World War II," Journal of Political Economy, pp. 228-248, April 1983.

[2] R. D. Huang, R. W. Masulis, and H. R. Stoll, "Energy shocks and financial markets." Journal of Futures Markets, vol. 16, pp. 1-27, 1996.

[3] M. Nandha and R. Faff, "Does oil move equity prices? A global view," Energy Economics, vol. 30, pp. 986-997, 2008.

[4] C. M. Jones and G. Kaul, "Oil and the stock markets," Journal of Finance, vol. 51, no. 2, pp. 463-491, 1996.

[5] P. Evangelia, "Oil price shocks, stock market, economic activity and employment in Greece," Energy Economics, vol. 23, pp. 511-532, 2001.

[6] C. Juncal and P. G. Fernando, "Do oil price shocks matter? Evidence for some European countries," Energy Economics, vol. 25, pp. 137-154, 2003.

[7] S. K. Mohanty , M. Nandha, A. Q. Turkistani, and M. Y. Alaitani, "Oil price movements and stock market returns: Evidence from Gulf Cooperation Council (GCC) countries," Global Finance Journal, vol. 22, pp. 42-55, 2011.

[8] M. E. H Arouri, A. Lahiani, and D.K. Nguyen, "Return and volatility transmission between world oil prices and stock markets of the GCC countries," Economic Modeling, vol. 28, pp. 1815-1825. 2011.

[9] R. Masih, S. Peters, and L. De Mello, "Oil price volatility and stock price fluctuations in an emerging market: Evidence from South Korea," Energy Economics, vol. 33, pp. 975-986, 2011.

[10] T. K. Jayaraman and C. K. Choong, "Growth and oil price: A study of causal relationships in small Pacific Island countries," Energy Policy, vol. 37, pp. 2182-2189, 2009

[11] S. A. Basher, and P. Sadorsky, " Oil price risk and emerging stock markets," Global FinanceJournal, vol. 17, pp. 224-251, 2006.

[12] J. D. Hamilton, "This is what happened to oil price-macroeconomic relationship," Journal of Monetary Economics, vol. 38, pp. 215-220, 1996.

[13] J. Federer, "Oil Price Volatility and Macroeconomy," Journal of Macroeconomics, vol. 18, pp. 1-26, 1996.

[14] P. Sadorsky, "Assessing the impact of oil prices on firms of different sizes; it is tough being in the middle," in Energy Policy, pp. 3854-3861.

[15] J. Park, and R. Ratti, "Oil price shocks and stock markets in the U.S. and 13 European countries," Energy Economics, vol. 30, pp. 2587-2608, 2008.

[16] B. S. Bernanke, "Irreversibility, Uncertainty, and Cyclical Investment," Quarterly Journal of Economics, vol. 98, no. 1, pp. 85-106, February 1083.

[17] E. Zivot and K. Andrews, "Further evidence on the great crash, the oil price shock, and the unit root hypothesis,"Journal of Business and Economic Statistics, vol. 10, no. 10, pp. 251-270, 1992.

[18] T. Bollerslev, "A Conditionally Heteroskedastic Time Series Model for Speculative Prices and Rates of Return," The Review of Economics and Statistics, vol. 69, no. 3, pp. 542-547, 1987.

[19] D. B. Nelson, "Conditional heteroskedasticity in asset returns: a new approach," Econometrica, vol. 59, no. 2, pp. 347-370, March 1991. 


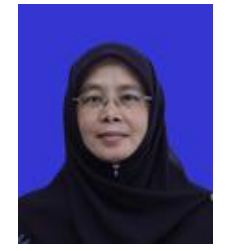

Hawati Janor earned her Ph.D (Finance) from Science University of Malaysia, Master in Finance (St Louis University, Missouri and BSc in Business Studies (Indiana University, Bloomington, Indiana USA), an Associate Professor at the National University of Malaysia. She has published and reviewed articles for local and international journals in the area of financial market, financial services, international finance and risk management.

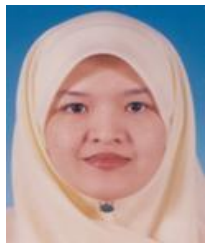

Aisyah Abdul-Rahman is currently an Associate Professor at the National University of Malaysia (UKM). Her research interests are bank risk management, bank efficiency, financial economics and corporate finance. She has studied in Lehigh University, Pennsylvania, U.S (1995-1997), National University of Malaysia (1997-1999).

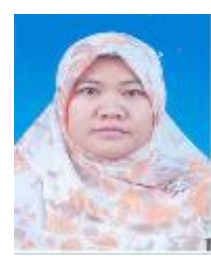

Ruzita Abdul Rahim attained her BS (Finance); MBA (Corp. Finance) from the State University of New York and her PhD (Investment).from the National University of Malaysia. She has published a number of articles on initial public offerings and capital structure; currently the Chief Editor of Jurnal Pengurusan, a Scopus indexed journal published by the UKM Publisher.

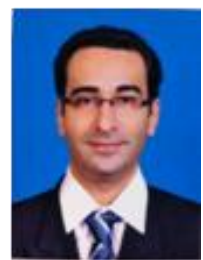

Ehsan Hosseinidoust is currently doing his $\mathrm{PhD}$ at the Faculty of Economics and Management, national university of Malaysia. He is familiar with different methods of stock markets modeling and forecasting which includes artificial neural networks, fuzzy logic and hybrid systems. 